\title{
Pyramiding Quantitative Resistance with a Major Resistance Gene in Apple: From Ephemeral to Enduring Effectiveness in Controlling Scab
}

Pauline Lasserre-Zuber, IRHS, Agrocampus-Ouest, INRA, Université d'Angers, SFR 4207 QuaSaV, 49071, Beaucouzé, France; present address: INRA, UMR 1095, Genetics, Diversity and Ecophysiology of Cereals, 63100, Clermont-Ferrand, France; Valérie Caffier, ${ }^{\dagger}$ IRHS, Agrocampus-Ouest, INRA, Université d'Angers, SFR 4207 QuaSaV, 49071, Beaucouzé, France; René Stievenard, CRRG, Centre Régional de Ressources Génétiques, Ferme du Héron, Chemin de la ferme de Lenglet, 59650, Villeneuve d'Ascq, France; Arnaud Lemarquand, UE0449 Unité Expérimentale Horticole, INRA, SFR 4207 QuaSaV, 49071, Beaucouzé, France; and Bruno Le Cam and Charles-Eric Durel, IRHS, Agrocampus-Ouest, INRA, Université d'Angers, SFR 4207 QuaSaV, 49071, Beaucouzé, France

\begin{abstract}
Genetic resistance is a useful strategy to control plant disease, but its effectiveness may be reduced over time due to the emergence of pathogens able to circumvent the defenses of the plant. However, the pyramiding of different resistance factors in the same plant can improve the effectiveness and durability of the resistance. To investigate the potential for this approach in apple to control scab disease we surveyed scab incidence in

two experimental orchards located at a distance of more than $300 \mathrm{~km}$ planted with apple genotypes carrying quantitative resistance and major gene resistance alone or in combination. Our results showed that the effectiveness of pyramiding in controlling scab was dependent on the site and could not be completely explained by the effectiveness level of the resistances alone.
\end{abstract}

The control of plant diseases by chemical products presents risks to human health and the ecological environment. Furthermore, these treatments can be ineffective if they are not used at the appropriate time or if the pathogens adapt and become resistant. Plant genetic resistance constitutes an environmentally friendly way to control disease and to reduce chemical inputs. Plant resistance can be described by two traits: (1) its phenotype with either a complete or partial level of resistance, and (2) its mode of heredity with either a continuous or a bimodal distribution between resistant and susceptible phenotypes in a progeny (Niks et al. 2015). Plant resistance is generally classified in two extreme categories: qualitative resistance conditioned by a single gene (i.e., major gene) and quantitative resistance conditioned by multiple genes of partial effect (i.e., Quantitative Trait Locus = QTL), with possibilities of intermediate types of resistances between these two categories (Poland et al. 2009; Stuthman et al. 2007). Genetically homogeneous crops with qualitative resistance induce strong directional selection on pathogen populations when they are deployed at a large scale and can result in resistance breakdown (Bus et al. 2011; Peressotti et al. 2010; Rouxel et al. 2003). Quantitative resistance has been frequently considered to be more durable than qualitative resistance (Lindhout 2002; Parlevliet 2002; Stuthman et al. 2007). However, it was postulated that quantitative resistance might also exert selection on pathogen populations (Gandon and Michalakis 2000; Parlevliet and Zadoks 1977). Indeed, it was shown experimentally in several pathosystems that quantitative resistance can also be eroded, for instance for Mycosphaerella graminicola on wheat (Cowger and Mundt 2002), lettuce mosaic virus on lettuce (Pink et al. 1992), Phytophthora infestans on potato (Andrivon et al. 2007; Montarry et al. 2008), Plasmopara viticola on grape (Delmas et al. 2016; Delmotte et al. 2014), and Venturia inaequalis on apple (Caffier et al. 2014, 2016). As

${ }^{\dagger}$ Corresponding author: V. Caffier; E-mail: valerie.caffier@inra.fr

The first two authors contributed equally to this work.

Funding: This work was funded by the CTPS programme "Durabilité des résistances variétales à des bioagresseurs 2006-2008" and the ANR grant, “ANR-05-PADD-05, CEDRE.”

Accepted for publication 23 April 2018.

(C) 2018 The American Phytopathological Society a consequence, both types of resistance may be eroded or overcome more or less rapidly according to the evolutionary potential of the pathogen, the host characteristics, and the agronomic practices. It is therefore necessary to develop strategies of resistance gene management that can improve the durability of resistance (Fabre et al. 2012; Mundt 2014; Sapoukhina et al. 2009; Sapoukhina et al. 2013).

Pyramiding genes of resistance in one cultivar is one of these strategies and is now feasible by marker-assisted breeding (Pilet-Nayel et al. 2017; Pink 2002). Several studies have demonstrated that combining resistance factors increases resistance effectiveness, either by cumulating major genes (Hittalmani et al. 2000; Koide et al. 2010; Tan et al. 2010), QTL (Castro et al. 2003; Hamon et al. 2010; Laloi et al. 2017; Richardson et al. 2006), or major genes and QTL (Eibach et al. 2007; Tabien et al. 2002). It has been experimentally observed that combinations of major genes and QTL can increase both resistance effectiveness and durability, for instance for Leptosphaeria maculans on rapeseed (Delourme et al. 2014), Microcyclus ulei on rubber (Le Guen et al. 2011), Globodera pallida on potato (Fournet et al. 2013), Meloidogyne species on pepper (Barbary et al. 2014), and Potato virus Y on pepper (Palloix et al. 2009; Quenouille et al. 2014). Indeed, major genes are totally effective to control the avirulent fraction of the pathogen population, whereas QTLs reduce the pathogen population size, which limits the selection for virulent isolates and maintains a partial effectiveness of the resistance toward the virulent isolates (Delourme et al. 2014). Theoretical studies indicate that durability of cultivars pyramiding resistances will depend on the way that the resistance genes are employed (Bourget et al. 2013). If each resistance gene is used separately, concomitantly, or before the use of cultivars pyramiding resistances, then the pathogen will be able to overcome the resistance by incrementally stacking virulences (Ayliffe et al. 2008; Pink 2002; Stuthman 2002), either by independent successive gain of virulence in the same strain or by sexual recombination between monovirulent strains. It should be noted that the durability of resistance pyramiding may depend on the genetic structure of the pathogen populations and ability of pathogen populations carrying single mutations to recombine, but this point has not yet been explored experimentally.

Here we investigated the effectiveness and durability of combining one major gene with two QTLs in the apple scab pathosystem. Apple scab, caused by the fungus Venturia inaequalis, is one of the most important diseases in commercial orchards in all temperate countries, because it strongly reduces fruit quality, which is vital for fresh market sales. Disease control today generally depends on the use of fungicides, spraying up to 20 treatments per year (Sauphanor et al. 
2009). The perennial trait of apple necessitates genotypes that can maintain resistance over many years. Major resistance genes have been identified in wild or domesticated apple species (Bus et al. 2011; Gessler et al. 2006; Soufflet-Freslon et al. 2008). The Rvi6 $(=V f)$ major resistance gene has been widely used in apple breeding programs during the last 50-60 years (Laurens 1999), but this monogenic resistance has been overcome by the pathogen (Bus et al. 2011; Lemaire et al. 2016). Many QTLs, including specific and broadspectrum QTLs, have also been identified (Calenge et al. 2004; Durel et al. 2003; Lê Van et al. 2013; Liebhard et al. 2003a; SouffletFreslon et al. 2008). The combination of two broad-spectrum resistance QTLs, F11 and F17, has already been shown to be eroded in experimental trials (Caffier et al. 2014). Thus, our aim was to evaluate the utility of pyramiding Rvi6 with QTLs F11 and F17, in two unsprayed orchards where resistance effectiveness of these QTLs and this major gene has already been challenged.

\section{Materials and Methods}

Plant material. A cross between cv. Prima and cv. Fiesta was carried out by the former CPRO-DLO, which is now part of Wageningen-UR Plant Breeding, The Netherlands (Maliepaard et al. 1998). These progeny (referred to as the "J progeny") segregate for two major genes, Rvil (=Vg) and Rvi6 (=Vf), and two broadspectrum QTLs, since cv. Prima carries Rvil and Rvi6 (Durel et al. 2000; Maliepaard et al. 1998) and cv. Fiesta carries two QTLs on linkage groups 11 and 17 (referred to as F11 and F17 in the present study) (Durel et al. 2003, 2004; Liebhard et al. 2003b). Using available molecular markers for the initial and curated marker positions published in Maliepaard et al. (1998) and Schouten et al. (2012), respectively, we selected 22 apple genotypes that carried either no favorable allele for QTL or for Rvi6 (Class-0), two favorable alleles for both QTLs F11 and F17 only (Class-QTL), favorable allele for Rvi6 only (Class-R), and favorable alleles for F11, F17, and Rvi6 (ClassRQTL), from the 161 available progenies. As Rvil is largely overcome in $V$. inaequalis populations, we considered that this major gene had no effect, and that the classes with Rvil and Rvi6 represented the effect of Rvi6. The number of genotypes per combination varied from five to seven (Table 1).

Orchard network. During winter 2003-2004, each genotype was planted in two experimental orchards located at a distance of more than $300 \mathrm{~km}$, representing two different environments and climates (Angers in northwestern France and Villeneuve d'Ascq in the north of France, later referred to as "Villeneuve"). In each orchard, three replicates per genotype were planted in a randomized three-block design after grafting onto the apple rootstock, 'Pajam 2.' The distance between the trees in a row was $1.5 \mathrm{~m}$ in Villeneuve and $1 \mathrm{~m}$ in Angers; the distance between the rows was $4 \mathrm{~m}$. Pesticides were applied when necessary, but no fungicide treatment was applied against scab.

Disease assessment. Scab incidence was scored on each tree in June after the period of primary infection in 2006-2008 at both sites. In Villeneuve, data from 2007 could not be interpreted because of a very low level of disease on the susceptible trees. In Angers, where

Table 1. Description of the apple genotypes of cv. Prima $\times \mathrm{cv}$. Fiesta progeny used in the present study

\begin{tabular}{lcccc}
\hline Resistance factors & Class-0 & Class-R & Class-QTL & Class-RQTL \\
\hline Rvi6 & $-^{\mathrm{a}}$ & $+^{\mathrm{b}}$ & - & + \\
F11 & - & - & + & + \\
F17 & - & - & + & + \\
& $\mathrm{J} 25$ & $\mathrm{~J} 3$ & $\mathrm{~J} 28$ & $\mathrm{~J} 46$ \\
& $\mathrm{~J} 32$ & $\mathrm{~J} 43$ & $\mathrm{~J} 63$ & $\mathrm{~J} 52$ \\
Genotypes $^{\mathrm{c}}$ & $\mathrm{J} 51$ & $\mathrm{~J} 83$ & $\mathrm{~J} 80$ & $\mathrm{~J} 104$ \\
& $\mathrm{~J} 61$ & $\mathrm{~J} 101$ & $\mathrm{~J} 90$ & $\mathrm{~J} 122$ \\
& $\mathrm{~J} 108$ & $\mathrm{~J} 103$ & $\mathrm{~J} 115$ & $\mathrm{~J} 158$ \\
& $\mathrm{~J} 119$ & & & \\
\hline
\end{tabular}

\footnotetext{
a Absence of the resistance factor.

${ }^{\mathrm{b}}$ Presence of the resistance factor.

${ }^{\mathrm{c}}$ Apple progenies of the cross between cv. Prima and cv. Fiesta.
}

the orchard was maintained after the end of the project, an additional assessment was carried out in 2012. On each tree, disease incidence was scored using an ordinal scale adapted from Lateur and Populer (1994). This scale consists of nine levels, described as intervals around the following values: $0 \%, 1 \%, 3 \%, 12.5 \%, 25 \%, 37.5 \%, 50 \%$, $75 \%$, and $90 \%$ scabbed leaves.

Statistical analysis. All statistical analyses were performed on the variable "disease incidence." Within each site and each year, the four classes of genotypes were compared for their disease incidence using a linear mixed effect model LME (Pinheiro and Bates 2000). The 'genotype' was treated as a random factor nested in the class of genotypes, and 'block' as a fixed factor. The model was fitted by maximizing the log-likelihood, and the best model was selected using the Bayesian Information Criterion after including each factor ('class of genotypes' and 'block') through an ascendant selection (Pinheiro and Bates 2000). The data were transformed into arcsine square root to normalize and homogenize the residuals. The resistance of Class-R, Class-QTL, or Class-RQTL was considered as effective if "disease incidence" was significantly different from "disease incidence" of Class-0. All statistical analyses were performed with R software, version 3.1.2 (R Core Team 2016), using the 'nlme' package (Pinheiro et al. 2016).

\section{Results}

In both sites, the level of disease on the control (Class-0) was high with fluctuations from year to year ranging from 51 to $83 \%$ scabbed leaves.

In Angers, the resistance based on Rvi6 (Class-R) was completely effective in 2006 with no scabbed leaves (Fig. 1A). This resistance was still effective in 2007, but a higher level of disease was observed (22\% scabbed leaves). This resistance became ineffective by 2008 (67\% scabbed leaves). The QTL combination F11F17 (Class-QTL) significantly reduced the disease each year compared with Class- 0 , even if the level of control decreased slowly over time (not shown in the present study, see Caffier et al. 2014). In 2006, the pyramiding of Rvi6 and F11F17 (Class-RQTL) was completely effective, with no scabbed leaves, due to the effectiveness of Rvi6. In 2007, this

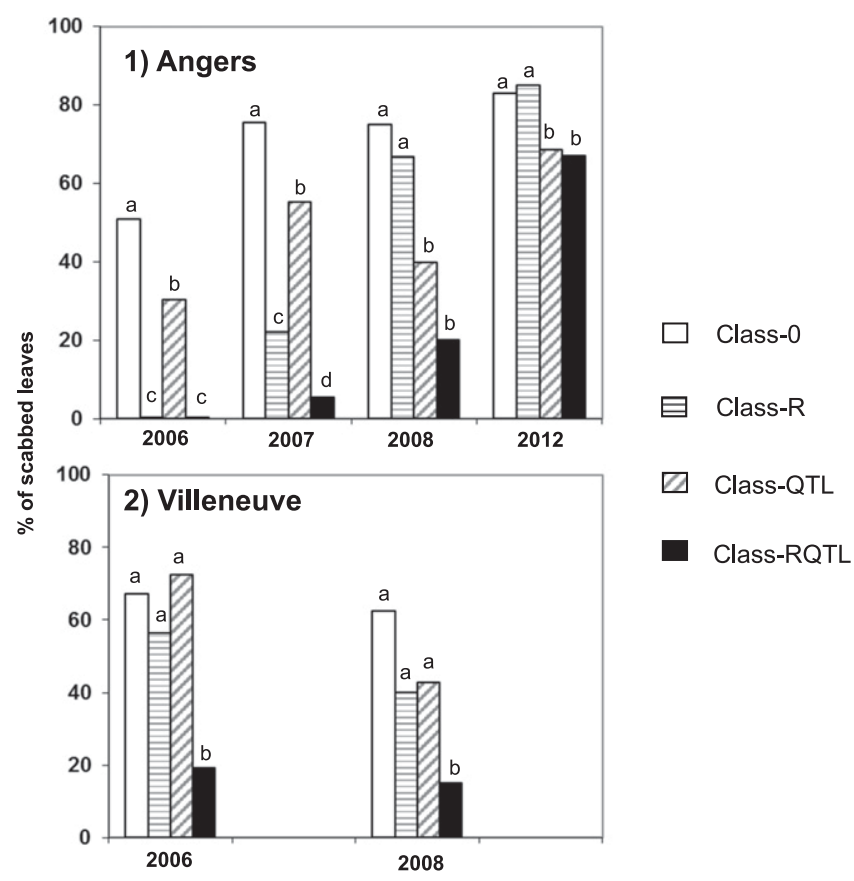

Fig. 1. Bar plots of apple scab incidence in two French orchards situated in: 1) Angers and 2) Villeneuve d'Ascq, for four classes of apple genotypes of the cv. Prima $x$ cv. Fiesta progeny: Class- 0 with no resistance factor, Class-R carrying the major resistance gene Rvi6, Class-QTL carrying the resistance QTL F11 and F17, and Class-RQTL carrying the pyramiding of Rvi6 with F11 and F17. Different letters indicate significant differences between disease incidence of the four classes for each year and each site with linear mixed-effect modeling $(P<0.05)$. 
pyramiding was significantly more effective (6\% scabbed leaves) than the resistance factors Rvi6 (Class-R with $22 \%$ scabbed leaves) or F11F17 (Class-QTL with 55\% scabbed leaves) alone. In 2008 and 2012, the resistance of Class-RQTL was still effective, with 20 and $64 \%$ scabbed leaves, respectively, compared with 75 and $83 \%$ for Class-0. However, the added value of Rvi6 was lost from 2008, while the effect of F11F17 remained with no significant difference between Class-RQTL and Class-QTL in 2008 and in 2012.

By contrast, in Villeneuve, both the major resistance Rvi6 (Class$\mathrm{R}$ ) and the QTL combination F11F17 (Class-QTL) were ineffective from the beginning of the experiment with more than $40 \%$ scabbed leaves. However, the apple genotypes carrying the pyramiding of Rvi6 and F11F17 (Class-RQTL) were significantly less diseased than Class-0 with less than $20 \%$ scabbed leaves for the two observed years, 2006 and 2008 (Fig. 1B).

\section{Discussion}

We evaluated the effectiveness of pyramiding quantitative resistance with a major resistance gene in two contrasting situations: one site (Angers) where the resistance factors alone were progressively overcome during the experiment trial, and one site (Villeneuve) where the resistance factors alone were already overcome when the experiment started (Caffier et al. 2014). Our results showed the effectiveness of pyramiding resistances for controlling scab in both sites, but to a different extent depending on the site. In Angers, the added value of pyramiding quantitative resistance with a major gene to control scab was ephemeral and disappeared when the level of disease control based on resistance factors alone decreased; whereas in Villeneuve, the pyramiding (Class-RQTL) remained effective both in 2006 and 2008, even if the resistance factors alone were not effective compared with Class-0.

These results are in agreement with other studies suggesting pyramiding QTLs with major resistance genes improves effectiveness and increases durability of resistance (Delourme et al. 2014; Le Guen et al. 2011; Quenouille et al. 2014). The effectiveness of pyramiding may be due to the low probability of a pathogen strain to accumulate independent mutations necessary to overcome all resistance genes in the pyramid (Mundt 2014), the reduction in the pathogen size population, or the diversification in the selection pressures exerted on the pathogen population (Pilet-Nayel et al. 2017). It is surprising, however, that the added value of pyramiding was maintained in Villeneuve; whereas it was lost in Angers. Indeed, at the Villeneuve site, the effectiveness of pyramiding the Rvi6 gene with QTLs was observed although apple genotypes with single noneffective resistance factors (Class-R or Class-QTL) were planted in the same orchard, which putatively facilitates stacking pathogenicity loci by mating. In such a situation, we could have expected disease control associated with pyramiding to decrease or be completely lost over time (Ayliffe et al. 2008; Pink 2002; Stuthman 2002), which was not observed. We assume that the effectiveness of resistance observed at this site was probably due to a lack of recombination between pathogen populations growing on class- $\mathrm{R}$ and populations growing on class-QTL. Indeed, a strong genetic differentiation was observed in the northwest of France between populations virulent toward Rvi6 and populations avirulent toward Rvi6 (Gladieux et al. 2011). At the Angers site, the improved resistance associated with pyramiding instead of single resistance factors was also observed in 2007 at the beginning of Rvi6 breakdown, but was lost from 2008 , with the level of disease control associated with pyramiding QTLs and the major gene (Class-RQTL) becoming similar to the level of disease control observed with the QTLs (Class-QTL) alone. At this site, Leroy et al. (2016) showed a low genetic differentiation between populations virulent toward Rvi6 and populations avirulent toward Rvi6 due to recombination between the two populations. Such a recombination may have resulted in the development of strains that were well adapted to all resistance factors incorporated in the pyramiding. Our results suggest that the effectiveness of pyramiding resistance genes depends not only on the way the resistance genes are used (Ayliffe et al. 2008; Bourget et al. 2013; Pink 2002; Stuthman 2002) but also on the capacity of pathogen populations carrying virulence and aggressiveness traits to recombine. We assume that the more gene flow that occurs between populations able to overcome different resistances, the more quickly the resistance of the pyramiding will be eroded.

Even in the case of ephemeral effectiveness, these results are promising for the development of environmentally friendly strategies to control apple scab and to reduce chemical treatments. Indeed, a previous study, Didelot et al. (2016), showed that the breakdown of the major resistance Rvi6 by virulent isolates could be delayed by the removal of leaf litter in autumn associated with spraying of fungicides in the case of moderate or high risks of scab infection. We can expect that the association of all these control methods, i.e., pyramiding of quantitative resistance with major resistance genes, sanitation, and chemical treatment applied only in case of great risk of scab infection, will provide a sustainable management of disease in a low-fungicide-input system, which is crucial for a perennial plant.

\section{Acknowledgments}

We thank Wageningen-UR Plant Breeding for the availability of the apple progeny of cv. Prima $\times \mathrm{cv}$. Fiesta and especially Eric van de Weg for the sharing/use of molecular marker data for this family. We thank Eric van de Weg and Jason Shiller for helpful comments on the manuscript. We thank Mathieu Lascostes from CRRG for his contribution to the planting of the experimental orchard at Villeneuve d'Asca and the phenotyping. We thank Philippe Billy, Christophe Brouard, Serge Brunet, and Christophe Vilfroy from INRA Experimental Unit UEH for participating to the phenotyping and taking care of the experimental orchard located in Angers. We thank Abou Kouassi and Amidou N'Diaye for their contribution in the phenotyping during their post-doc stay at INRA-Angers. We also thank Elisa Ravon, Fabienne Mathis and Caroline Denancé from IRHS for complementary genotyping.

\section{Literature Cited}

Andrivon, D., Pilet, F., Montarry, J., Hafidi, M., Corbière, R., Achbani, E. H., Pellé, R., and Ellissèche, D. 2007. Adaptation of Phytophthora infestans to partial resistance in potato: Evidence from French and Moroccan populations. Phytopathology 97:338-343.

Ayliffe, M., Singh, R., and Lagudah, E. 2008. Durable resistance to wheat stem rust needed. Curr. Opin. Plant Biol. 11:187-192.

Barbary, A., Palloix, A., Fazari, A., Marteu, N., Castagnone-Sereno, P., and DjianCaporalino, C. 2014. The plant genetic background affects the efficiency of the pepper major nematode resistance genes $\mathrm{Mel}$ and $\mathrm{Me3}$. Theor. Appl. Genet. 127:499-507.

Bourget, R., Chaumont, L., and Sapoukhina, N. 2013. Timing of pathogen adaptation to a multicomponent treatment. PLoS One 8:e71926.

Bus, V. G. M., Rikkerink, E. H. A., Caffier, V., Durel, C. E., and Plummer, K. M 2011. Revision of the nomenclature of the differential host-pathogen interactions of Venturia inaequalis and Malus. Annu. Rev. Phytopathol. 49: 391-413.

Caffier, V., Lasserre-Zuber, P., Giraud, M., Lascostes, M., Stievenard, R., Lemarquand, A., van de Weg, E., Expert, P., Denancé, C., Didelot, F., Le Cam, B., and Durel, C. 2014. Erosion of quantitative host resistance in the apple - Venturia inaequalis pathosystem. Infect. Genet. Evol. 27:481-489.

Caffier, V., Le Cam, B., Al Rifaï, M., Bellanger, M. N., Comby, M., Denance, C., Didelot, F., Expert, P., Kerdraon, T., Lemarquand, A., Ravon, E., and Durel, C. E. 2016. Slow erosion of a quantitative apple resistance to Venturia inaequalis based on an isolate-specific Quantitative Trait Locus. Infect. Genet. Evol. 44: 541-548.

Calenge, F., Faure, A., Goerre, M., Gebhardt, C., van de Weg, W. E., Parisi, L., and Durel, C. E. 2004. Quantitative trait loci (QTL) analysis reveals both broadspectrum and isolate-specific QTL for scab resistance in an apple progeny challenged with eight isolates of Venturia inaequalis. Phytopathology 94: 370-379.

Castro, A. J., Chen, X., Hayes, P. M., and Johnston, M. 2003. Pyramiding quantitative trait locus (QTL) alleles determining resistance to barley stripe rust: Effects on resistance at the seedling stage. Crop Sci. 43:651-659.

Cowger, C., and Mundt, C. C. 2002. Aggressiveness of Mycosphaerella graminicola isolates from susceptible and partially resistant wheat cultivars. Phytopathology 92:624-630.

Delmas, C. E. L., Fabre, F., Jolivet, J., Mazet, I. D., Richart Cervera, S., Delière, L., and Delmotte, F. 2016. Adaptation of a plant pathogen to partial host resistance: Selection for greater aggressiveness in grapevine downy mildew. Evol. Appl. 9 709-725.

Delmotte, F., Mestre, P., Schneider, C., Kassemeyer, H. H., Kozma, P., RichartCervera, S., Rouxel, M., and Delière, L. 2014. Rapid and multiregional adaptation to host partial resistance in a plant pathogenic oomycete: Evidence from European populations of Plasmopara viticola, the causal agent of grapevine downy mildew. Infect. Genet. Evol. 27:500-508.

Delourme, R., Bousset, L., Ermel, M., Duffé, P., Besnard, A. L., Marquer, B., Fudal, I., Linglin, J., Chadoeuf, J., and Brun, H. 2014. Quantitative resistance affects the speed of frequency increase but not the diversity of the virulence 
alleles overcoming a major resistance gene to Leptosphaeria maculans in oilseed rape. Infect. Genet. Evol. 27:490-499.

Didelot, F., Caffier, V., Orain, G., Lemarquand, A., and Parisi, L. 2016. Sustainable management of scab control through the integration of apple resistant cultivars in a low-fungicide input system. Agric. Ecosyst. Environ. 217:41-48.

Durel, C. E., Calenge, F., Parisi, L., van de Weg, W. E., Kodde, L. P., Liebhard, R., Gessler, C., Thiermann, M., Dunemann, F., Gennari, F., Tartarini, S., and Lespinasse, Y. 2004. An overview of the position and robustness of scab resistance QTLs and major genes by aligning genetic maps of five apple progenies. Acta Hortic.: 135-140.

Durel, C. E., Parisi, L., Laurens, F., van de Weg, W. E., Liebhard, R., and Jourjon, M. F. 2003. Genetic dissection of partial resistance to race 6 of Venturia inaequalis in apple. Genome 46:224-234.

Durel, C. E., van de Weg, W. E., Venisse, J. S., and Parisi, L. 2000. Localisation of a major gene for apple scab resistance on the European genetic map of the Prima $\times$ Fiesta cross. IOBC WPRS Bull. 23:245-248.

Eibach, R., Zyprian, E., Welter, L., and Topfer, R. 2007. The use of molecular markers for pyramiding resistance genes in grapevine breeding. Vitis 46: $120-124$.

Fabre, F., Rousseau, E., Mailleret, L., and Moury, B. 2012. Durable strategies to deploy plant resistance in agricultural landscapes. New Phytol. 193:1064-1075.

Fournet, S., Kerlan, M. C., Renault, L., Dantec, J. P., Rouaux, C., and Montarry, J. 2013. Selection of nematodes by resistant plants has implications for local adaptation and cross-virulence. Plant Pathol. 62:184-193.

Gandon, S., and Michalakis, Y. 2000. Evolution of parasite virulence against qualitative or quantitative host resistance. Proc. R. Soc. Lond., B 267:985-990.

Gessler, C., Patocchi, A., Sansavini, S., Tartarini, S., and Gianfranceschi, L. 2006. Venturia inaequalis resistance in apple. Crit. Rev. Plant Sci. 25:473-503.

Gladieux, P., Guerin, F., Giraud, T., Caffier, V., Lemaire, C., Parisi, L., Didelot, F., and Le Cam, B. 2011. Emergence of novel fungal pathogens by ecological speciation: Importance of the reduced viability of immigrants. Mol. Ecol. 20: 4521-4532.

Hamon, C., Baranger, A., Miteul, H., Lecointe, R., Le Goff, I., Deniot, G., Onfroy, C., Moussart, A., Prosperi, J. M., Tivoli, B., Delourme, R., and Pilet-Nayel, M. L. 2010. A complex genetic network involving a broad-spectrum locus and strain-specific loci controls resistance to different pathotypes of Aphanomyces euteiches in Medicago truncatula. Theor. Appl. Genet. 120:955-970.

Hittalmani, S., Parco, A., Mew, T. V., Zeigler, R. S., and Huang, N. 2000. Fine mapping and DNA marker-assisted pyramiding of the three major genes for blast resistance in rice. Theor. Appl. Genet. 100:1121-1128.

Koide, Y., Kawasaki, A., Telebanco-Yanoria, M. J., Hairmansis, A., Nguyet, N. T. M., Bigirimana, J., Fujita, D., Kobayashi, N., and Fukuta, Y. 2010. Development of pyramided lines with two resistance genes, Pish and Pib, for blast disease (Magnaporthe oryzae B. Couch) in rice (Oryza sativa L.). Plant Breed. 129: 670-675.

Laloi, G., Vergne, E., Durel, C.-E., Le Cam, B., and Caffier, V. 2017. Efficiency of pyramiding of three quantitative resistance loci to apple scab. Plant Pathol. 66: 412-422.

Lateur, M., and Populer, C. 1994. Screening fruit tree genetic resources in Belgium for disease resistance and other desirable characters. Euphytica 77:147-153.

Laurens, F. 1999. Review of the current apple breeding programmes in the world: Objectives for scion cultivar improvement. Acta Hortic.: 163-170.

Le Guen, V., Garcia, D., Doaré, F., Mattos, C. R. R., Condina, V., Couturier, C., Chambon, A., Weber, C., Espéout, S., and Seguin, M. 2011. A rubber tree's durable resistance to Microcyclus ulei is conferred by a qualitative gene and a major quantitative resistance factor. Tree Genet. Genomes 7:877-889.

Lê Van, A., Caffier, V., Lasserre-Zuber, P., Chauveau, A., Brunel, D., Le Cam, B., and Durel, C. 2013. Differential selection pressures exerted by host resistance quantitative trait loci on a pathogen population: A case study in an apple $\times$ Venturia inaequalis pathosystem. New Phytol. 197:899-908.

Lemaire, C., De Gracia, M., Leroy, T., Michalecka, M., Lindhard-Pedersen, H., Guerin, F., Gladieux, P., and Le Cam, B. 2016. Emergence of new virulent populations of apple scab from nonagricultural disease reservoirs. New Phytol. 209:1220-1229.

Leroy, T., Caffier, V., Celton, J. M., Anger, N., Durel, C. E., Lemaire, C., and Le Cam, B. 2016. When virulence originates from nonagricultural hosts: Evolutionary and epidemiological consequences of introgressions following secondary contacts in Venturia inaequalis. New Phytol. 210:1443-1452.

Liebhard, R., Kellerhals, M., Pfammatter, W., Jertmini, M., and Gessler, C. 2003a. Mapping quantitative physiological traits in apple (Malus $\times$ domestica Borkh.). Plant Mol. Biol. 52:511-526.

Liebhard, R., Koller, B., Patocchi, A., Kellerhals, M., Pfammatter, W., Jermini, M., and Gessler, C. 2003b. Mapping quantitative field resistance against apple scab in a 'Fiesta' $\times$ 'Discovery' progeny. Phytopathology 93:493-501.

Lindhout, P. 2002. The perspectives of polygenic resistance in breeding for durable disease resistance. Euphytica 124:217-226.

Maliepaard, C., Alston, F. H., Van Arkel, G., Brown, L. M., Chevreau, E., Dunemann, F., Evans, K. M., Gardiner, S., Guilford, P., Van Heusden, A. W., Janse, J., Laurens, F., Lynn, J. R., Manganaris, A. G., den Nijs, A. P. M., Periam, N., Rikkerink, E., Roche, P., Ryder, C., Sansavini, S., Schmidt, H., Tartarini, S., Verhaegh, J. J., Vrielink-Van Ginkel, M., and King, G. J. 1998. Aligning male and female linkage maps of apple (Malus pumila Mill.) using multi-allelic markers. Theor. Appl. Genet. 97:60-73.
Montarry, J., Glais, I., Corbiere, R., and Andrivon, D. 2008. Adaptation to the most abundant host genotype in an agricultural plant-pathogen system - potato late blight. J. Evol. Biol. 21:1397-1407.

Mundt, C. C. 2014. Durable resistance: A key to sustainable management of pathogens and pests. Infect. Genet. Evol. 27:446-455.

Niks, R. E., Qi, X. Q., and Marcel, T. C. 2015. Quantitative resistance to biotrophic filamentous plant pathogens: Concepts, misconceptions, and mechanisms. Annu. Rev. Phytopathol. 53:445-470.

Palloix, A., Ayme, V., and Moury, B. 2009. Durability of plant major resistance genes to pathogens depends on the genetic background, experimental evidence and consequences for breeding strategies. New Phytol. 183:190-199.

Parlevliet, J. E. 2002. Durability of resistance against fungal, bacterial and viral pathogens; present situation. Euphytica 124:147-156.

Parlevliet, J. E., and Zadoks, J. C. 1977. The integrated concept of disease resistance: A new view including horizontal and vertical resistance in plants. Euphytica 26:5-21

Peressotti, E., Wiedemann-Merdinoglu, S., Delmotte, F., Bellin, D., Di Gaspero, G., Testolin, R., Merdinoglu, D., and Mestre, P. 2010. Breakdown of resistance to grapevine downy mildew upon limited deployment of a resistant variety. BMC Plant Biol. 10:147.

Pilet-Nayel, M. L., Moury, B., Caffier, V., Montarry, J., Kerlan, M. C., Fournet, S., Durel, C. E., and Delourme, R. 2017. Quantitative resistance to plant pathogens in pyramiding strategies for durable crop protection. Front. Plant Sci. 8:1838.

Pinheiro, J., Bates, D., Debroy, S., and Sarkar, D. 2016. Nlme: Linear and nonlinear mixed effects models. R package version 3.1-128. https://cran. r-project.org/web/packages/nlme/index.html

Pinheiro, J. C., and Bates, D. M. 2000. Mixed-Effects Models in S and S-PLUS Springer-Verlag, New York, USA. https://www.springer.com/us/book/ 9780387989570

Pink, D. A. C. 2002. Strategies using genes for non-durable disease resistance. Euphytica 124:227-236.

Pink, D. A. C., Lot, H., and Johnson, R. 1992. Novel pathotypes of lettuce mosaic virus - breakdown of a durable resistance? Euphytica 63:169-174.

Poland, J. A., Balint-Kurti, P. J., Wisser, R. J., Pratt, R. C., and Nelson, R. J. 2009. Shades of gray: The world of quantitative disease resistance. Trends Plant Sci. 14:21-29.

Quenouille, J., Paulhiac, E., Moury, B., and Palloix, A. 2014. Quantitative trait loci from the host genetic background modulate the durability of a resistance gene: A rational basis for sustainable resistance breeding in plants. Heredity 112 : 579-587.

R Core Team. 2016. R: A Language and Environment for Statistical Computing. R Foundation for Statistical Computing, Vienna, Austria. ([http://www.R-project. org])

Richardson, K. L., Vales, M. I., Kling, J. G., Mundt, C. C., and Hayes, P. M. 2006 Pyramiding and dissecting disease resistance QTL to barley stripe rust. Theor. Appl. Genet. 113:485-495.

Rouxel, T., Penaud, A., Pinochet, X., Brun, H., Gout, L., Delourme, R., Schmit, J., and Balesdent, M. H. 2003. A 10-year survey of populations of Leptosphaeria maculans in France indicates a rapid adaptation towards the Rlm1 resistance gene of oilseed rape. Eur. J. Plant Pathol. 109:871-881.

Sapoukhina, N., Durel, C. E., and Le Cam, B. 2009. Spatial deployment of genefor-gene resistance governs evolution and spread of pathogen populations. Theor. Ecol. 2:229-238.

Sapoukhina, N., Paillard, S., Dedryver, F., and de Vallavieille-Pope, C. 2013 Quantitative plant resistance in cultivar mixtures: Wheat yellow rust as a modeling case study. New Phytol. 200:888-897.

Sauphanor, B., Dirwimmer, C., Boutin, S., Chaussabel, A. L., Dupont, N., Fauriel, J., Gallia, V., Lambert, N., Navarro, E., Parisi, L., Plenet, D., Ricaud, V., Sagnes, J. L., Sauvaitre, D., Simon, S., Speich, P., and Zavagli, F. 2009. Analyse comparative de différents systèmes en arboriculture fruitière. In: Ecophyto R\&D: Vers des systèmes de culture économes en produits phytosanitaires, rapport d'expertise collective. T. Volay, ed. INRA, France.

Schouten, H. J., van de Weg, W. E., Carling, J., Khan, S. A., Mckay, S. J., Van Kaauwen, M. P. W., Wittenberg, A. H. J., Koehorst-Van Putten, H. J. J. Noordijk, Y., Gao, Z. S., Rees, D. J. G., Van Dyk, M. M., Jaccoud, D., Considine, M. J., and Kilian, A. 2012. Diversity arrays technology (DArT) markers in apple for genetic linkage maps. Mol. Breed. 29:645-660.

Soufflet-Freslon, V., Gianfranceschi, L., Patocchi, A., and Durel, C. E. 2008. Inheritance studies of apple scab resistance and identification of Rvi14, a new major gene that acts together with other broad-spectrum QTL. Genome 51: 657-667.

Stuthman, D. D. 2002. Contribution of durable disease resistance to sustainable agriculture. Euphytica 124:253-258

Stuthman, D. D., Leonard, K. J., and Miller-Garvin, J. 2007. Breeding crops for durable resistance to disease. Adv. Agron. 95:319-367.

Tabien, R. E., Li, Z., Paterson, A. H., Marchetti, M. A., Stansel, J. W., and Pinson, S. R. M. 2002. Mapping QTLs for field resistance to the rice blast pathogen and evaluating their individual and combined utility in improved varieties. Theor. Appl. Genet. 105:313-324.

Tan, M. Y. A., Hutten, R. C. B., Visser, R. G. F., and Van Eck, H. J. 2010. The effect of pyramiding Phytophthora infestans resistance genes R (Pi-mcd1) and R (Pi-ber) in potato. Theor. Appl. Genet. 121:117-125. 